\title{
REFLEXOS TERRITORIAIS DO PROCESSO DE REESTRUTURAÇÃO INDUSTRIAL EM PORTUGAL CONTINENTAL NA DÉCADA DE OITENTA ${ }^{1}$
}

\author{
EDUARDA MARQUES DA COSTA ${ }^{2}$ \\ NUNO MARQUES DA COSTA ${ }^{2}$
}

\begin{abstract}
Resumo - Com este trabalho pretende-se identificar a dinâmica sectorial e territorial da indústria transformadora em Portugal Continental no período compreendido entre $1982 \mathrm{e}$ 1993. Através do método de alteração proporcional (Shift-Share Analysis), são identificadas as principais transformações na estrutura sectorial do emprego na indústria transformadora, bem como as alterações regionais na sua distribuição.
\end{abstract}

Palavras-chave: análise de Shift-Share, vantagens locativas, reestruturação industrial, especialização industrial.

\begin{abstract}
Industrial Restructuring In Portugal In THE Eighties - This paper analyses the territorial changes in manufacturing activity in mainland Portugal during the eighties. A shift-share analysis was applied to regional employment. Its results are presented and the main reasons that explain regional differences are discussed.
\end{abstract}

Key-words: Shift-Share analysis, location advantages, industrial restructuring, industrial specialisation.

\section{INTRODUÇÃO}

Com este trabalho pretende-se identificar e caracterizar a dinâmica sectorial e territorial da indústria transformadora em Portugal Continental no período compreendido entre 1982 e 1993.

A análise tem por base metodológica o modelo de alteração proporcional (Shift-Share Analysis), relativo às modificações do emprego por distrito, na indústria transformadora, no período assinalado. A escolha desta unidade espacial permite a comparação com os trabalhos de JENSEN-BUTLER e PIRES (1983) e JENSEN-BUTLER e FERRÃO (1986) anteriormente elaborados sobre a mesma temática e que, de igual forma, utilizaram o distrito como unidade de análise.

A informação estatística referente ao emprego tem como base os quadros de pessoal do Ministério do Emprego e Segurança Social (MESS). Com o objectivo de complementar a análise, recorreu-se à construção de alguns indicadores que nos permitissem avaliar a dinâmica económica das empresas dos vários ramos em estudo (Produtividade ${ }^{3}$, Rendibilidade ${ }^{4}$ e Taxa de Investimento ${ }^{5}$ ). Estes indicadores

1 Este artigo foi efectuado no âmbito do projecto "Desenvolvimento industrial e território", JNICT, $\mathrm{PCSH} / \mathrm{C} / \mathrm{GEO} / 715 / 93$.

2 Assistentes da Universidade de Lisboa. Investigadores do CEG. Centro de Estudos Geográficos, Faculdade de Letras de Lisboa, Cidade Universitária, 1699 LISBOA Codex. Tel: (351-1) 79402 18; Fax: (351-1) 79386 90. e-mail: ceg@mail.telepac.pt.

$$
3 \frac{\mathrm{VAB}}{\text { Emprego }}
$$


foram construídos a partir da informação presente nas Estatísticas Industriais do Instituto Nacional de Estatística (INE). Embora reconhecendo a existência de diferenças entre as duas fontes de informação, os dados do INE permitem espelhar o comportamento económico geral dos ramos e sub-ramos em análise, complementando a visão dada pelo emprego.

\section{1 - A DINÂMICA INDUSTRIAL PORTUGUESA NOS ANOS OITENTA - O PADRÃO DE EVOLUÇÃO SECTORIAL}

As transformações da economia portuguesa na década de setenta foram marcadas pela perda do mercado ultramarino, pela convulsão política e social do período pós-revolucionário, pela crise económica mundial e pelo aumento da competitividade internacional. Estes factores condicionaram a evolução ocorrida na década seguinte, que se caracterizou por um redirecionamento das exportações portuguesas para os mercados europeu e americano, expansão do mercado interno e a adesão de Portugal à Comunidade Europeia.

A integração de Portugal foi determinante para a evolução da economia portuguesa, nomeadamente, pelas melhorias introduzidas ao nível das grandes infra-estruturas de transporte, concessão de incentivos financeiros à actividade industrial, apoio aos agentes institucionais de carácter local (municípios e associações empresariais) e promoção do investimento em geral. Estas medidas muito contribuíram para a retoma verificada a partir da segunda metade da década de oitenta (BOURA, COSTA e JACINTO, 1993).

Para além dos aspectos anteriormente referidos, há ainda a considerar condicionantes de carácter externo às quais Portugal não esteve alheio e que foram, por um lado, a crescente internacionalização do capital e da produção, e por outro, o reforço da competitividade internacional. Esta terá de ser considerada segundo dois vectores diferenciados: competitividade baseada na inovação do produto e do processo produtivo e competitividade assente nos custos do factor trabalho. Neste quadro, as transformações na estrutura industrial portuguesa nos anos oitenta caracterizaram-se pela reestruturação produtiva de alguns dos sub-ramos, bem como pelo reenquadramento de Portugal na nova divisão internacional do trabalho.

\section{1 - Principais transformações na estrutura do emprego industrial}

$\mathrm{Na}$ década de oitenta, o emprego industrial aumentou cerca de $6 \%$, o que representou um abrandamento do ritmo de crescimento relativamente à década anterior, que se situou perto dos $21 \%$ (cf. FERRÃO e JENSEN-BUTLER, 1986). Outro aspecto diferenciado foi o declínio de vários ramos industriais, nomeadamente as químicas, as metalúrgicas de base, o material de transporte e os têxteis, ao contrário do acréscimo generalizado verificado durante os anos setenta.

A análise conjugada da taxa de variação do emprego entre 1982 e 1993 e da importância relativa de cada ramo na indústria transformadora em 1993 (fig. 1), permite-nos identificar sete grupos com dinâmicas diferenciadas. Assim:

- com dinâmica de crescimento superior à média nacional;

$$
\begin{aligned}
& { }_{4} \frac{\text { VAB }- \text { Salários }}{\text { Salários }} \times 100 \\
& { }_{5} \frac{\text { FBCF }}{\text { VAB }} \times 100
\end{aligned}
$$


A. Ramos com assinalável importância em termos de emprego industrial (valores superiores a $6 \%$ ) e cuja dinâmica de crescimento na última década foi muito superior à média nacional (próximo da duplicação): vestuário e calçado;

B. Ramos cuja importância em termos de emprego oscila entre os 2 e os 5\% e cuja dinâmica de crescimento no período em estudo é superior à média nacional: sub-ramos das máquinas e outro material eléctrico, artes gráficas e publicações, mobiliário de madeira e as porcelanas e faianças;

C. Ramos com um reduzido peso em termos de emprego e uma taxa de variação próxima da média nacional: as bebidas, os plásticos e os couros;

- com dinâmica de crescimento inferior à média nacional;

D. Ramos com pouca participação para o emprego nacional (inferior a 2\%) com uma taxa de crescimento nula ou ligeiramente negativa: sub-ramos muito específicos como sejam o fabrico de instrumentos profissionais e científicos de aparelhos de medida de verificação, fotográficos e instrumentos de óptica, e ainda, as outras indústrias alimentares, os químicos (ex. agro-químicos, farmacêuticos e produtos biológicos) e as borrachas; 
Figura 1 - Relação entre a taxa de variação do emprego industrial em 1982-1993 e o peso de cada ramo no emprego industrial em 1993.

Figure 1 - Relationship between the industrial employment rate in 1982-93 and the share of employment in 1993.

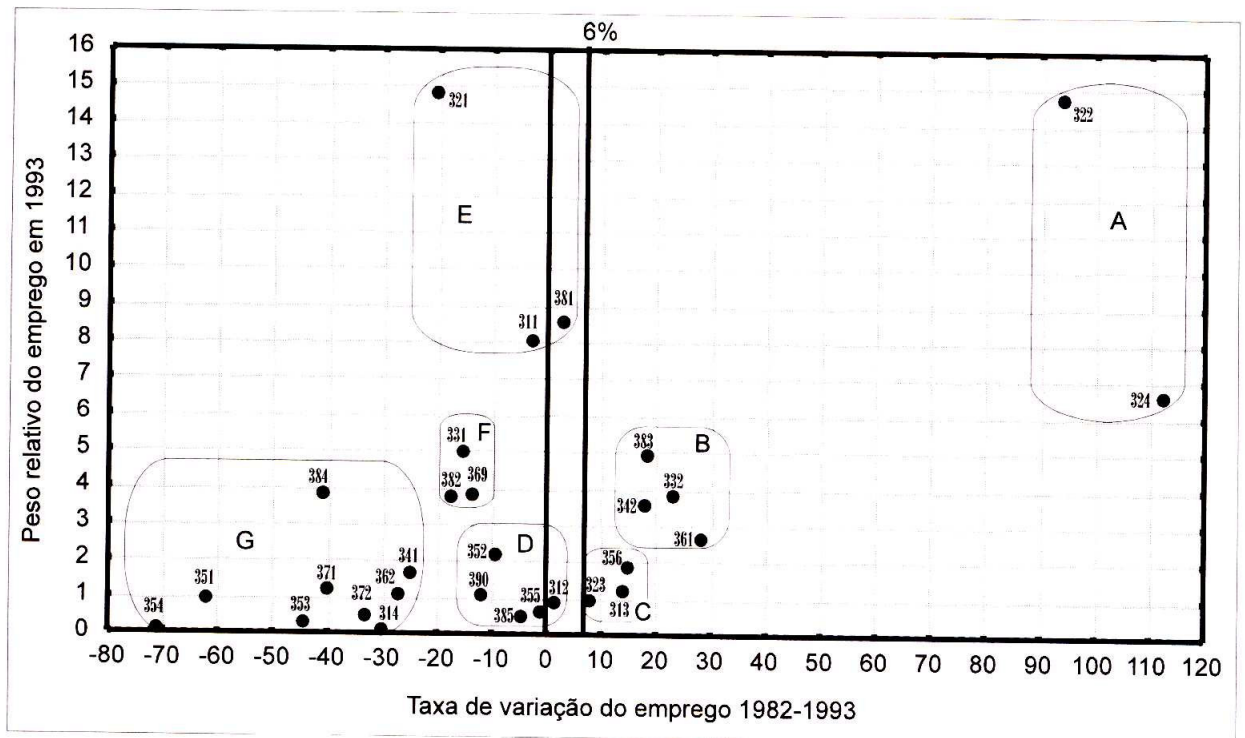

Fonte: MESS

311 - Indústrias Alimentares

312 - Outras Indústrias Alimentares

313 - Indústrias das Bebidas

314 - Indústria do Tabaco

321 - Indústrias Têxteis

322 - Fabricação de Artigos de Vestuário, com excepção do Calçado

323 - Indústria dos Curtumes e dos Artigos de Couro e dos seus Substitutos e de Pele, com excepção do Calçado e Outros Artigos de Vestuário

324 - Fabricação de Calçado, com excepção do Calçado Vulcanizado; de Borracha Moldada ou de Plástico e o Feito Inteiramente de Madeira

331 - Indústrias da Madeira; Fabrico de Artefactos de Madeira e de Cortiça, com excepção do Mobiliário

332 - Fabricação de Mobiliário, com excepção do Mobiliário Metálico e de Plástico Moldado

341 - Indústrias do Papel

342 - Artes Gráficas e Edição de Publicações

351 - Fabricação de Produtos Químicos Industriais

352 - Fabricação de Outros Produtos Químicos

353 - Refinarias de Petróleo

354 - Fabricação de Derivados Diversos de Petróleo e do Carvão

355 - Indústria da Borracha

356 - Fabricação de Artigos de Matérias Plásticas

361 - Fabricação de Porcelana, Faiança, Grés Fino e Olaria de Barro

362 - Fabricação do Vidro e de Artigos de Vidro

369 - Fabricação de Outros Produtos Minerais não Metálicos

371 - Indústrias Básicas de Ferro e Aço

372 - Indústrias Básicas de Metais não Ferrosos
381 - Fabricação de Produtos Metálicos, com excepção de Máquinas, Equipamento e Material de Transporte

382 - Fabricação de Máquinas não Eléctricas

383 - Fabricação de Máquinas, Aparelhos, Utensílios e Outro Material Eléctrico

384 - Construção de Material de Transporte

385 - Fabricação de Instrumentos Profissionais e Científicos e de Aparelhos de Medida, de Verificação, Fotográficos e de Instrumentos de Óptica

390 - Outras Indústrias Transformadoras 
E. Ramos com grande importância em termos de emprego mas onde se verificou uma taxa de crescimento nula ou ligeiramente negativa: têxtil, alimentares (311) e produtos metálicos;

F. Ramos cujo emprego representa 4 a $6 \%$ do emprego industrial e cuja dinâmica de crescimento no período em estudo é negativa: fabricação de produtos minerais não metálicos de apoio à construção civil (materiais de barro, cimento, cal e gesso), a fabricação de máquinas não eléctricas (motores, máquinas e equipamento agrícola e o fabrico e reparação de máquinas) e as indústrias da madeira e da cortiça;

G. Ramos com pouca importância em termos de emprego (com excepção para o material de transporte) e que apresentaram um comportamento bastante negativo na última década (decréscimos superiores a 20\%): tabaco, papel, químicos industriais, refinarias, produtos diversos derivados do petróleo e carvão, vidro, as básicas de metais ferrosos e não ferrosos e a construção de material de transporte.

Relativamente ao primeiro grupo (A) onde se encontram o vestuário e o calçado, o crescimento verificado nestes ramos consolidou a especialização sectorial que se veio a delinear ao longo das últimas décadas. Esta especialização traduziu-se a três níveis: reforço da componente do emprego industrial em valor absoluto, aumento do seu peso na estrutura sectorial e incremento da sua importância no conjunto das nossas exportações. Estes três aspectos revelam uma estagnação no processo de diversificação e modernização da estrutura produtiva e comercial nacional e, por outro lado, reflectem o aumento da dependência da indústria transformadora nacional em áreas cuja competitividade assenta no baixo custo da força de trabalho. Associado aos aspectos anteriormente referidos está o fenómeno da subcontratação que, segundo MARQUES (1992), surge nas suas formas mais tradicionais e precárias, predominantemente dependente da procura de salários baixos.

O segundo grupo (B) apresenta igualmente um comportamento positivo em termos de crescimento. Este acréscimo tem duas componentes distintas: por um lado, resultou do aumento da procura interna, por outro, dependeu do aumento da procura internacional e da contínua internacionalização de certos segmentos da produção, caso das cablagens e outro material eléctrico e electrónico, que conquistaram a atenção do investimento estrangeiro (VALE, 1991). Esta situação não é nova, pois as indústrias de produção de material eléctrico são desde meados de sessenta, indústrias fortemente ligadas a empresas multinacionais, com elevada representação nas exportações portuguesas e cuja competitividade tem tido por base os baixos custos do factor trabalho. O crescimento deste ramo inseriu-se numa lógica de abertura da economia ao exterior que favoreceu o crescimento das exportações industriais (MATOS, 1973). Na década de sessenta, as empresas de capital estrangeiro instaladas em Portugal representavam cerca de $75 \%$ das exportações dos ramos da produção de material eléctrico e electrónico e um valor idêntico da montagem de veículos automóveis (PIMENTA, 1984).

Também a cerâmica doméstica, decorativa e para a construção civil cresceu significativamente. Enquanto a faiança e a porcelana possuem uma taxa de exportação bastante elevada, a produção de pavimento-revestimento está muito virada para o aumento da procura do mercado interno. No entanto, a incapacidade de resposta ao aumento da procura, facilitou a penetração de produtos estrangeiros, nomeadamente espanhóis (pavimentos-revestimentos e loiças sanitárias) (MIE, 1990). 
No grupo B incluem-se ainda as artes gráficas e publicações, ramo que tem sofrido grandes transformações nos últimos anos. O desenvolvimento das telecomunicações e do sector terciário, acompanhados pela globalização da economia, promoveram grandes transformações neste ramo. Assim, a evolução ocorrida em Portugal traduz o processo de reestruturação por que passou e passa o ramo em termos internacionais, verificando-se uma deslocalização de unidades das grandes concentrações urbanas (Lisboa e Porto) para áreas imediatamente periféricas a estas, que possuem boa acessibilidade, facilidade de acesso à informação e se mantêm próximas dos grandes mercados. Outra característica a evidenciar é a tendência para a segmentação do processo produtivo, que tem alguma relevância na edição dos periódicos.

No terceiro grupo (C), contam-se as bebidas, os plásticos, os couros e curtumes. $\mathrm{O}$ primeiro é um ramo bastante heterógeneo pois engloba produtos que têm associadas estruturas de produção, de mercado, dimensão e graus de concentração bem diferenciados entre si. Dois factores foram determinantes para a evolução da produção de bebidas: a elevação do poder de compra, que se reflectiu directamente num aumento da procura deste tipo de bens e a afirmação de novos padrões de consumo expressos na vulgarização de produtos como sumos, concentrados, cerveja e águas de mesa nos hábitos alimentares. A propósito desta situação, refira-se que nos últimos anos, à diminuição da procura do vinho sobrepôs-se uma crescente procura de cerveja, cujo consumo se foi aproximando dos níveis europeus ${ }^{1}$.

A evolução do emprego no ramo dos plásticos resultou não só da expansão do mercado interno, mas também da procura por parte de outros ramos industriais. Os resultados dos couros e curtumes dependeram, em larga medida, da evolução do ramo do calçado que, como vimos anteriormente, teve na última década um forte incremento.

Com um crescimento abaixo da média nacional contam-se os Grupos D, E, F e G. Nestes incluem-se ramos muito diversificados, desde as indústrias pesadas às ligeiras mais tradicionais. Contudo, foram as indústrias pesadas aquelas que, de uma forma geral, sofreram maior transformação no emprego (Grupo G). Esta situação revelou a continuidade do processo de recessão que as indústrias pesadas sofreram durante a crise de setenta e que se agravou com a abertura dos mercados a Leste. Outro aspecto que explica a forte redução do emprego no sector pesado, é a elevada importância que estes ramos assumiam na estrutura do emprego industrial no início da década em estudo. Efectivamente, em 1982 estes ramos detinham um peso muito superior ao verificado no conjunto dos países industrializados. A revolução de Abril e o processo de nacionalizações desta decorrente, de certa forma «amorteceram» os efeitos da crise internacional, escalonando os seus impactes por um período superior ao verificado nos restantes países (que se estendeu ao longo dos anos oitenta).

$\mathrm{Na}$ década de oitenta há ainda a considerar dois outros factores condicionantes da evolução do emprego nestes ramos. Por um lado, a integração na Comunidade Europeia que acentuou a reestruturação do sector produtivo nacional (afectando com particular incidência as estruturas mais tradicionais e menos flexíveis), por outro, a aceleração da concentração do capital, traduzida na fusão de empresas que

\footnotetext{
${ }^{1}$ Em 1987 a capitação era de 47 litros/habitante, enquanto em 1989 estaria próxima dos 65 litros/habitante (MIE, 1990), valor que é ainda inferior à média europeia (apenas a Itália e a França, tal como nós, tradicionais produtores de vinho, apresentam valores de consumo de cerveja per capita inferiores a Portugal)
} 
assim se integraram em grandes grupos industriais. Este último factor é particularmente evidente nas indústrias químicas e nas de construção de material de transporte (caso da fabricação e montagem de veículos a motor), explicando-se a forte dependência nacional das estratégias delineadas pelos grupos industriais estrangeiros que possuem investimentos em Portugal

Nos últimos anos, ao encerramento de algumas unidades de montagem de veículos instaladas em Portugal, contrapôs-se o investimento (maioritariamente estrangeiro) nos ramos da fabricação de componentes, cuja produção se destinava à exportação. No início dos anos oitenta, muitas das empresas de produção de componentes estavam associadas a outras de montagem de veículos (caso da Renault), mas em finais de oitenta a situação alterou-se: o número de empresas aumentou e a produção virou-se para o exterior. A instalação em Palmela, de uma nova unidade de produção automóvel, resultado da joint-venture entre a Ford e a Volkswagen, constituiu uma excepção ao encerramento de unidades de produção e montagem de veículos. Esta unidade, que começou a produzir apenas em 26 de Abril de 1995 , permitiu a criação de mais de $3000^{2}$ postos de trabalho directos. No entanto, as expectactivas geradas, nomeadamente após a assinatura do contrato em 1991, contribuiram para o reforço do segmento das componentes onde se enquadram os pneus, sistemas eléctricos e electrónicos, peças plásticas, etc., sub-ramos onde a participação de capital estrangeiro é igualmente elevada.

Os restantes ramos que mais perderam emprego foram as indústrias tradicionais (Grupos E e F). São os casos dos têxteis, madeiras e cortiça, produtos metálicos e os vidros (que pelo volume de emprego perdido se incluíram no Grupo G). A incapacidade de algumas empresas se ajustarem à procura nacional e internacional, a concorrência europeia e, de uma maneira geral, o baixo nível de modernização empresarial, justificam a situação destes ramos. Por outro lado, os têxteis, nomeadamente os lanifícios, e os produtos metálicos foram privilegiados receptores de fundos comunitários para a sua reestruturação e modernização, que foram canalizados para a renovação e aquisição de bens de equipamento que vieram libertar mão-de-obra.

Incluídas nos grupos D e E, estão as indústrias alimentares (ramos 311 e 312 da CAE-Rev.1). A heterogeneidade deste ramo manifesta-se ao nível dos produtos. Assim, enquanto ocorre uma diminuição da procura interna para produtos como margarinas, óleos e farinhas, o consumo de produtos associados aos novos padrões de consumo como sejam os congelados, caldos, sopas, fermentos, condimentos e temperos, aumenta. Por outro lado, este é outro dos sectores em que a concorrência internacional se tem vindo a manisfestar de forma acentuada, quer pela penetração de produtos estrangeiros de marca, quer pela introdução de produtos brancos por via das redes internacionais de comércio e distribuição, que concorrem fortemente com o mercado nacional.

\footnotetext{
${ }^{2}$ O projecto inicial previa a criação de 5000 postos de trabalho directos e 7000 indirectos (CoSTA e VALE, 1995).
} 


\section{2 - A dimensão económica dos ramos}

A análise da evolução do emprego deve ser complementada por outros indicadores que nos permitam conhecer a dimensão económica dos vários ramos em estudo. Apenas há a referir duas limitações; a informação mais actualizada diz respeito ao ano de 1989 (o que se afasta consideravelmente de 1993, o último ano do período da análise anterior) e o nível de desagração da informação relativa aos ramos industriais é diferente do utilizado anteriormente. Assim, na análise do emprego foi possível identificar 29 ramos (correspondentes à CAE - Rev. 1 desagregada a três digitos) enquanto as estatísticas industriais consideram apenas 20 grupos que decorrem de agregações de ramos da CAE - Rev. 1. Isto condiciona a interpretação na medida em que ramos distintos como o têxtil e o vestuário ou a fabricação de produtos minerais não metálicos (onde se encontram desde as porcelanas aos cimentos) surgem agregados na informação fornecida pelo INE, podendo os índices por si só traduzir situações muito heterógeneas.

Os ramos com maiores índices de produtividade, em 1981 e 1989, são as refinarias de petróleo e o tabaco, logo seguidos das bebidas, dos minerais metálicos, químicos industriais e das artes gráficas e publicações, ramos que, pela sua natureza tecnológica e organizativa, apresentam maior intensificação de capital.

Em oposição encontramos as indústrias do têxtil, vestuário, couros e calçado, madeiras, cortiça e mobiliário cujos níveis de produtividade (sistematicamente inferiores à média nacional) têm vindo a decrescer nos últimos anos, Considerando que as dinâmicas de emprego são de crescimento (vestuário, calçado e mobiliário) ou de reduzido decréscimo (têxtil, madeira e cortiça), a sua evolução reflecte o fraco nível de investimento em capital, nomeadamente no início da década de oitenta (quadro I). Por outro lado, estes valores apontam ainda para um reforço da competitividade assente no factor trabalho (como comprovam também os baixos índices de rendibilidade). 
Quadro I - Índices de produtividade, rendibilidade e investimento por ramos em 1981 e 1989

(Total da Indústria Transformadora $=100$ )

Table I - Productivity, Rentability and Investment rates, 1981 and 1989

(Total of Manufacturing Industry $=100)$

\begin{tabular}{|c|c|c|c|c|c|c|}
\hline & & 1981 & & & 1989 & \\
\hline Ramos & $\begin{array}{c}\text { Produtivi- } \\
\text { dade }\end{array}$ & $\begin{array}{c}\text { Rendibili- } \\
\text { dade }\end{array}$ & $\begin{array}{c}\text { Tax. } \\
\text { Invest. }\end{array}$ & $\begin{array}{c}\text { Produtivi- } \\
\text { dade }\end{array}$ & $\begin{array}{c}\text { Rendibi- } \\
\text { lidade }\end{array}$ & $\begin{array}{c}\text { Tax. } \\
\text { Invest. }\end{array}$ \\
\hline Alimentação & 91,9 & 115,9 & 68,5 & 110,9 & 146,1 & 92,2 \\
\hline Bebidas & 221,7 & 328,4 & 87,4 & 223,7 & 278,7 & 158,0 \\
\hline Tabaco & 460,7 & 567,6 & 51,7 & 600,1 & 723,8 & 23,8 \\
\hline Têxtil e vestuário & 68,5 & 74,8 & 97,9 & 58,4 & 58,0 & 110,1 \\
\hline Curtumes, couros e calçado & 75,6 & 105,6 & 63,5 & 59,7 & 72,1 & 49,6 \\
\hline Madeira & 70,2 & 100,3 & 71,6 & 68,3 & 89,2 & 77,5 \\
\hline Mobiliário & 69,0 & 116,0 & 49,5 & 48,4 & 53,7 & 92,2 \\
\hline Papel, artes gráficas e publicações & 142,0 & 159,7 & 99,9 & 184,6 & 181,4 & 149,0 \\
\hline Químicos industriais & 106,4 & 31,2 & 317,0 & 190,7 & 128,6 & 79,8 \\
\hline Refinarias e outros produtos derivados do petróleo & 1509,1 & 1487,5 & 8,0 & 336,4 & 145,0 & 101,7 \\
\hline Borrachas & 105,9 & 74,7 & 112,2 & 101,5 & 77,5 & 121,3 \\
\hline Plásticos & 111,8 & 130,4 & 96,2 & 91,7 & 89,8 & 142,2 \\
\hline Minerais não metálicos & 106,1 & 102,5 & 94,7 & 118,3 & 123,2 & 123,2 \\
\hline Minerais metálicos & 140,9 & 119,1 & 209,4 & 129,3 & 91,2 & 112,9 \\
\hline Metálicas & 98,6 & 83,8 & 74,3 & 84,6 & 61,8 & 70,0 \\
\hline Máquinas não eléctricas & 101,8 & 66,8 & 74,2 & 90,7 & 53,9 & 61,1 \\
\hline Máquinas e outro material eléctrico & 123,0 & 96,1 & 71,5 & 131,6 & 93,2 & 81,7 \\
\hline Material de transporte & 94,3 & 4,6 & 104,2 & 102,5 & 40,3 & 50,4 \\
\hline Instrumentos profissionais e científicos & 74,1 & 43,0 & 54,7 & 72,7 & 43,6 & 47,2 \\
\hline Outras Ind. Transf. & 74,0 & 69,9 & 36,5 & 59,5 & 61,8 & 91,9 \\
\hline Total Ind. Transf. & 100,0 & 100,0 & 100,0 & 100,0 & 100,0 & 100,0 \\
\hline
\end{tabular}

Fonte: INE, Estatísticas Industriais.

Igualmente com uma produtividade abaixo da média nacional contavam-se, em 1989, os produtos metálicos, as máquinas não eléctricas e os plásticos. O perfil destes ramos evoluiu no sentido negativo pois, em 1981, eles alcançavam valores de produtividade ligeiramente acima da média nacional. A rendibilidade decresceu igualmente, o que pode ser explicado pelos fracos investimentos realizados. Efectivamente, com excepção dos plásticos cujos valores de investimento são próximos ou superiores à média nacional, nos restantes dois ramos os índices de investimento são inferiores à média nacional.

Nos ramos das alimentares, borracha, minerais não metálicos, metalúrgicas, máquinas, material eléctrico e material de transporte, verificaram-se ganhos de produtividade, que no caso das alimentares e do material de transporte foram muito significativos (em 1981, encontram-se abaixo da média nacional, situação que em 1989 se inverteu). Com excepção do material eléctrico, verificamos que os ganhos de produtividade foram acompanhados por uma redução do emprego, indiciando a ocorrência de um processo de reestruturação produtivo, basicamente assente na racionalização da actividade produtiva num contexto de progressiva concorrência internacional. 


\section{3 - Incentivos e dinâmica industrial}

Os investimentos realizados no âmbito dos vários programas comunitários de que Portugal beneficiou após a sua integração, constituiram uma oportunidade para a reestruturação da indústria portuguesa. Durante os anos oitenta, os principais instrumentos de apoio financeiro foram o Sistema Integrado de Incentivos ao Investimento Industrial (SIII - em funcionamento até ao segundo semestre de 1986), o Sistema de Estímulos de Base Regional (SEBR, em vigor até 1988), o Sistema de Incentivos de Base Regional (SIBR, iniciado em 1988) e o Programa Específico de Desenvolvimento da Indústria Portuguesa (PEDIP, iniciado em 1988) (BoURA, COSTA e JACINTO, 1990).

Os índices presentes no quadro I reportam-se a 1989, excluindo possíveis efeitos dos incentivos concedidos no âmbito do PEDIP e do SIBR, entre 1988 e 1992. A importância destes sistemas é assinalável, quer pelos montantes envolvidos, quer pelas novas empresas criadas. Veja-se o caso do PEDIP, cujo investimento total efectuado entre 1988 e 1992, no conjunto dos programas operacionais, ascendeu a mais de 924 milhões de contos (para 7330 projectos). Do conjunto de sub-programas do PEDIP, poderemos destacar o sub-programa 3.1 SINPEDIP (Sistema de Incentivos Financeiros do PEDIP), que teve como objectivo o apoio ao investimento produtivo. Neste sub-programa foram aprovados 3532 projectos que envolveram um investimento total (Comunitário, Público e Privado) de 583 milhões de contos (MIE, 1993). Na estrutura sectorial dos investimentos realizados no Sub-Programa 3.1, destacam-se os ramos do têxtil, vestuário e calçado (em particular a fiação e tecelagem), produtos minerais não metálicos, produtos metálicos, máquinas (em particular o material eléctrico) e construção de material de transporte (quadro II).

Para além do sub-programa 3.1., os ramos em destaque ainda foram objecto de outros apoios específicos: o sub-programa 3.3.1 - Lanifícios, para as metalúrgicas, metálicas, maquinaria e material de transporte, o sub-programa 3.3.2 - Fundição e o sub-programa 3.4 - Apoio a sectores específicos (tecnologias de informação, electrónica e bens de equipamento).

Quadro II - Projectos aprovados e Investimento total realizado no Programa 3 - Incentivo ao investimento produtivo, Sub-Programa 3.1 - SINPEDIP (1988-92), por ramo de actividade na indústria Table II - Projects and Investment by SINPEDIP, 1988-92

\begin{tabular}{|c|c|c|}
\hline Ramos da Indústria & $\begin{array}{l}\text { Projectos } \\
(\% \text { do total })\end{array}$ & $\begin{array}{l}\text { Investimento Total } \\
(\% \text { do total })\end{array}$ \\
\hline Extracção do carvão & 0,1 & 0,0 \\
\hline Extracção de minerais não metálicos e rochas industriais & 0,7 & 0,3 \\
\hline Indústrias da alimentação, bebidas e tabaco & 6,1 & 6,8 \\
\hline Indústrias têxteis, do vestuário e do couro & 24,0 & 18,6 \\
\hline Indústrias da madeira e da cortiça & 6,7 & 4,9 \\
\hline Indústrias do papel; artes gráficas e edição de publicações & 5,3 & 7,5 \\
\hline $\begin{array}{l}\text { Indústrias químicas dos derivados do petróleo e do carvão } \\
\text { e dos produtos de borracha e de plástico }\end{array}$ & 9,8 & 14,5 \\
\hline $\begin{array}{l}\text { Indústrias dos produtos minerais não metálicos, } \\
\text { com excepção dos derivados do petróleo bruto e do carvão }\end{array}$ & 11,8 & 15,1 \\
\hline Indústrias metalúrgicas de base & 3,0 & 2,3 \\
\hline $\begin{array}{l}\text { Fabricação de produtos metálicos e de máquinas, equipamento e } \\
\text { material de transporte }\end{array}$ & 31,2 & 29,2 \\
\hline Outras indústrias transformadoras & 1,3 & 0,8 \\
\hline Total & 100,0 & 100,0 \\
\hline
\end{tabular}

Fonte: Adaptado de MIE (1993) - PEDIP, Relatório de Execução, 1988-1992, Vol. I: 56. 
Apesar dos apoios concedidos, a análise da evolução do emprego aponta para um reforço da especialização produtiva em ramos tradicionais fortemente intensivos em trabalho, caso do vestuário e do calçado, mantendo-se as vulnerabilidades da capacidade competitiva da economia portuguesa.

\section{2- REFLEXOS TERRITORIAIS DO PROCESSO DE REESTRUTURAÇÃO PRODUTIVA}

Para a análise dos reflexos territoriais da reestruturação produtiva na década de oitenta, recorreu-se ao método de alteração proporcional (Shift-Share Analysis). Este compara a alteração verificada na economia regional face a uma economia de referência, normalmente a nacional, permitindo identificar as características particulares de cada região.

O crescimento do emprego regional (G) deriva do comportamento do Regional Share $(\mathrm{R})^{3}$ e da Alteração Relativa Líquida $(\mathrm{ARL})^{4}$, sendo que a adição destes dois elementos (R+ARL) nos dá G.

O Regional Share representa a parte correspondente à região se todos os ramos crescessem ao ritmo nacional, ou seja, é o incremento resultante da aplicação da taxa de crescimento da economia de referência. Assim, verificar-se-ia uma relação directa entre o crescimento e o valor de partida do emprego em cada região, assumindo-se a existência de uma igual distribuição sectorial e com um comportamento regional uniforme. Se o comportamento das regiões e dos ramos fosse igual, o crescimento do emprego seria então igual à parte regional do crescimento nacional, ou seja o Regional Share (i.e, se a taxa de crescimento nacional foi de $6 \%$, então o aumento em todas as regiões seria de $6 \%$ ).

A Alteração Relativa Líquida (ou Regional Shift), reflecte a diferença entre o crescimento observado para cada região e o hipotético crescimento se na região este tivesse ocorrido segundo o ritmo nacional. Assim, a análise permite identificar quais as regiões que melhor e pior comportamento apresentaram no conjunto de referência. No entanto, temos de ter em conta que a ARL constitui um valor que não reflecte as diferenças relativas de cada uma das regiões. Ela será tanto maior quanto maiores forem os efectivos em jogo. Assim, pequenas diferenças podem traduzir alterações importantes para regiões onde os valores do emprego são reduzidos. De alguma forma poderemos ver pela comparação entre as taxas de variação do emprego entre 1982 e 1993 e a ARL (fig. 2 e 3). Apesar dos pequenos quantitativos da ARL, a variação do emprego foi bastante importante para alguns distritos como sejam Bragança e Évora.

Os conjuntos de distritos formados por Lisboa e Setúbal e por Beja, Faro e Bragança, apresentaram na última década um comportamento negativo; o crescimento do emprego não só foi abaixo da média, como este diminuiu em termos absolutos. Dos distritos que apresentaram uma dinâmica de crescimento superior à nacional, salientam-se Braga, Aveiro e Porto (distritos onde o peso do emprego era já importante) e Leiria, Viseu e Viana do Castelo, onde a indústria transformadora detinha um peso menor. Este padrão de crescimento mostra o reforço da litoralização das actividades industriais e o consequente aumento dos desequilíbrios na distribuição territorial do emprego.

\footnotetext{
${ }^{3} \mathrm{R}=\left(\left(\mathrm{E}_{\mathrm{n} 1} / \mathrm{E}_{\mathrm{n} 0}\right) \mathrm{x} \mathrm{E}_{\mathrm{r} 0}\right)-\mathrm{E}_{\mathrm{r} 0}$ em que $\mathrm{E}_{\mathrm{r}^{-}}$Emprego regional, $\mathrm{E}_{\mathrm{n}}$ Emprego nacional e 0 e 1 momento inicial e momento final, respectivamente.

${ }^{4} \mathrm{E}_{\mathrm{r} 1}-\left(\mathrm{E}_{\mathrm{n} 1} / \mathrm{E}_{\mathrm{n} 0}\right) \mathrm{xE}_{\mathrm{r} 0}$ em que $\mathrm{E}_{\mathrm{r}}-$ Emprego regional, $\mathrm{E}_{\mathrm{n}}$ Emprego nacional e 0 e 1 momento inicial e momento final, respectivamente.
} 


\section{1 - As componentes estrutural e diferencial}

A ARL pode decompor-se em duas componentes distintas: a componente estrutural (proportional shift $)^{5}$ e a diferencial (differential shift) ${ }^{6}$. Se a primeira permite identificar a influência da composição da estrutura industrial em cada região, pela presença de sectores de elevado crescimento nacional (valor positivo) ou de reduzido crescimento (valor negativo), a segunda traduz as diferenças regionais do crescimento sectorial, evidenciando vantagens ou desvantagens (valor positivo ou negativo) específicas de cada região, sendo assim possível designá-la por componente locativa.

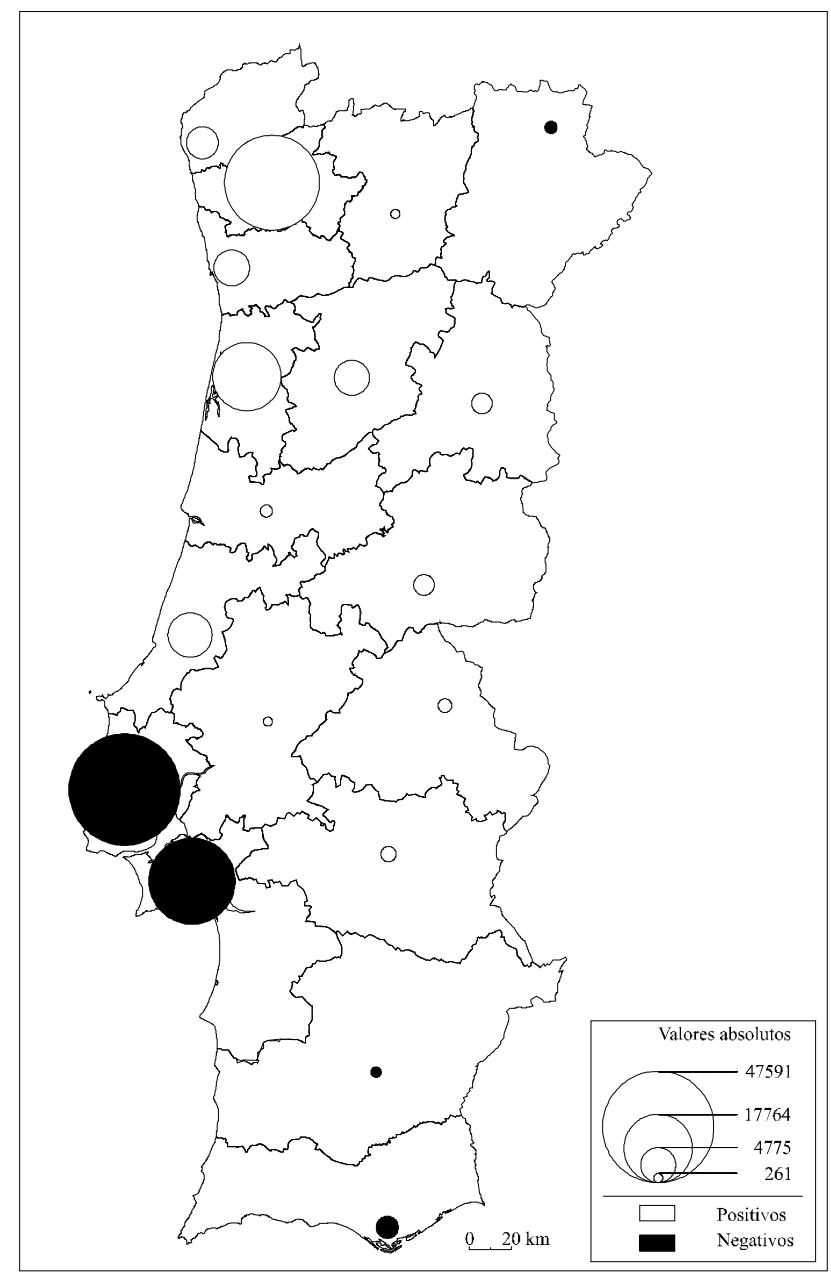

Figura 2 - Alteração relativa líquida por distritos, 1982-93.

Figure 2 - Regional shift by «distrito», 1982-93.

\footnotetext{
$5 \sum_{\mathrm{i}=1}^{\mathrm{n}}\left(\left(\right.\right.$ En1i/En0i) - (En1/En0) $x$ Er0i em que $\mathrm{E}_{\mathrm{r}}-$ Emprego regional, $\mathrm{E}_{\mathrm{n}}$ Emprego nacional, 0 e 1

momento inicial e momento final respectivamente e i cada ramo de $\mathrm{n}$ ramos em análise

$6 \sum_{i=1}^{n} E r 1 i-(E n 1 i / E n 0 i) x E r 0 i$
} 


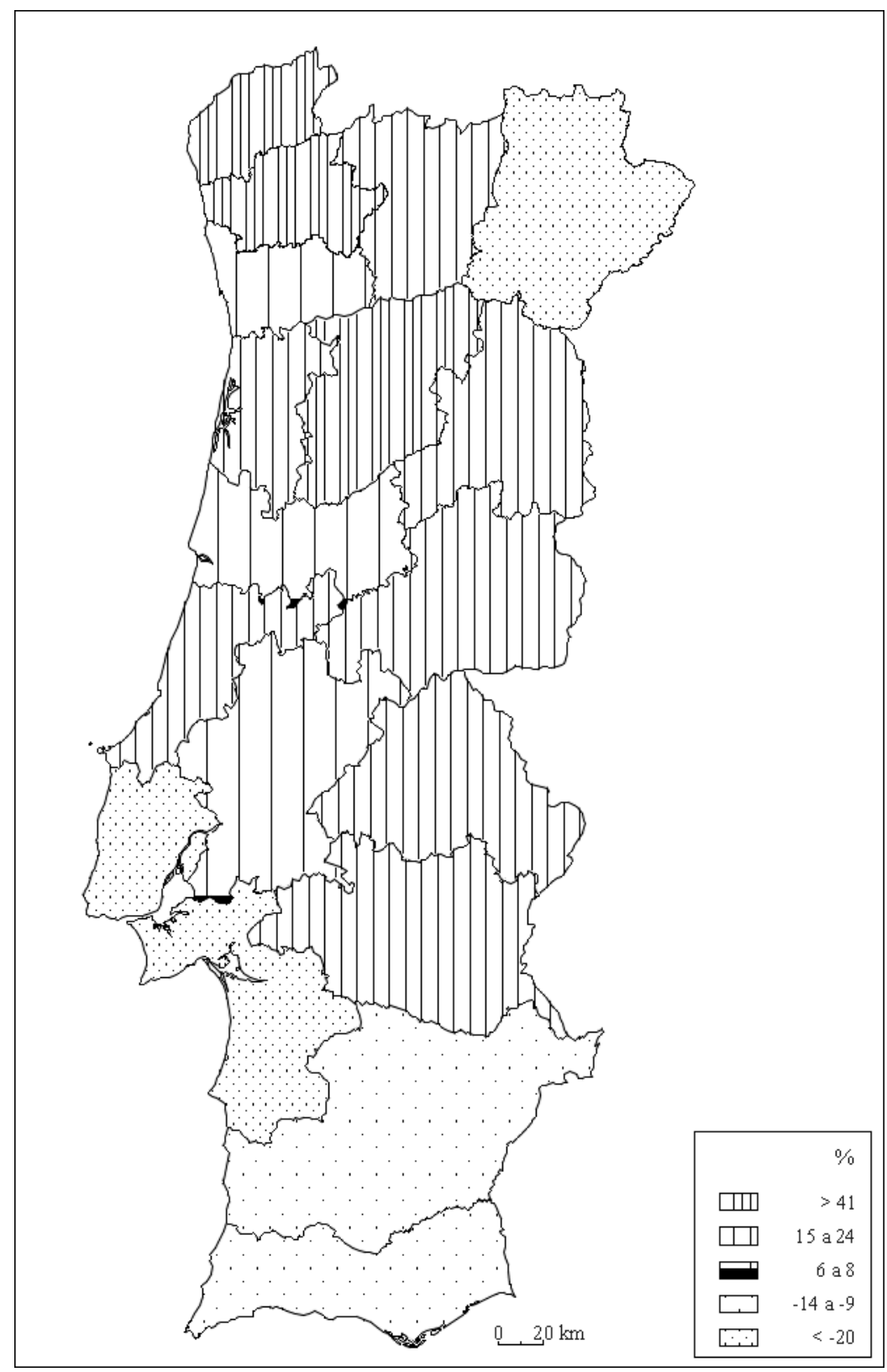

Figura 3 - Taxa de variação do emprego por distritos, 1982-93 (\%).

Figure 3 - Employment variation rate by «distrito», 1982-93 (\%).

A distribuição da componente estrutural mostra-nos que esta é negativa para grande parte dos distritos, sendo apenas positiva para o Porto, Aveiro, Castelo Branco e Évora. Tal facto explica-se pela presença dos ramos do vestuário, do calçado (Aveiro e Porto), ramos estes que apresentaram os maiores crescimentos no período em análise, e material eléctrico (Évora), que apresentou também um valor acima da média nacional (fig. 4). Este padrão de distribuição é bastante diferente 


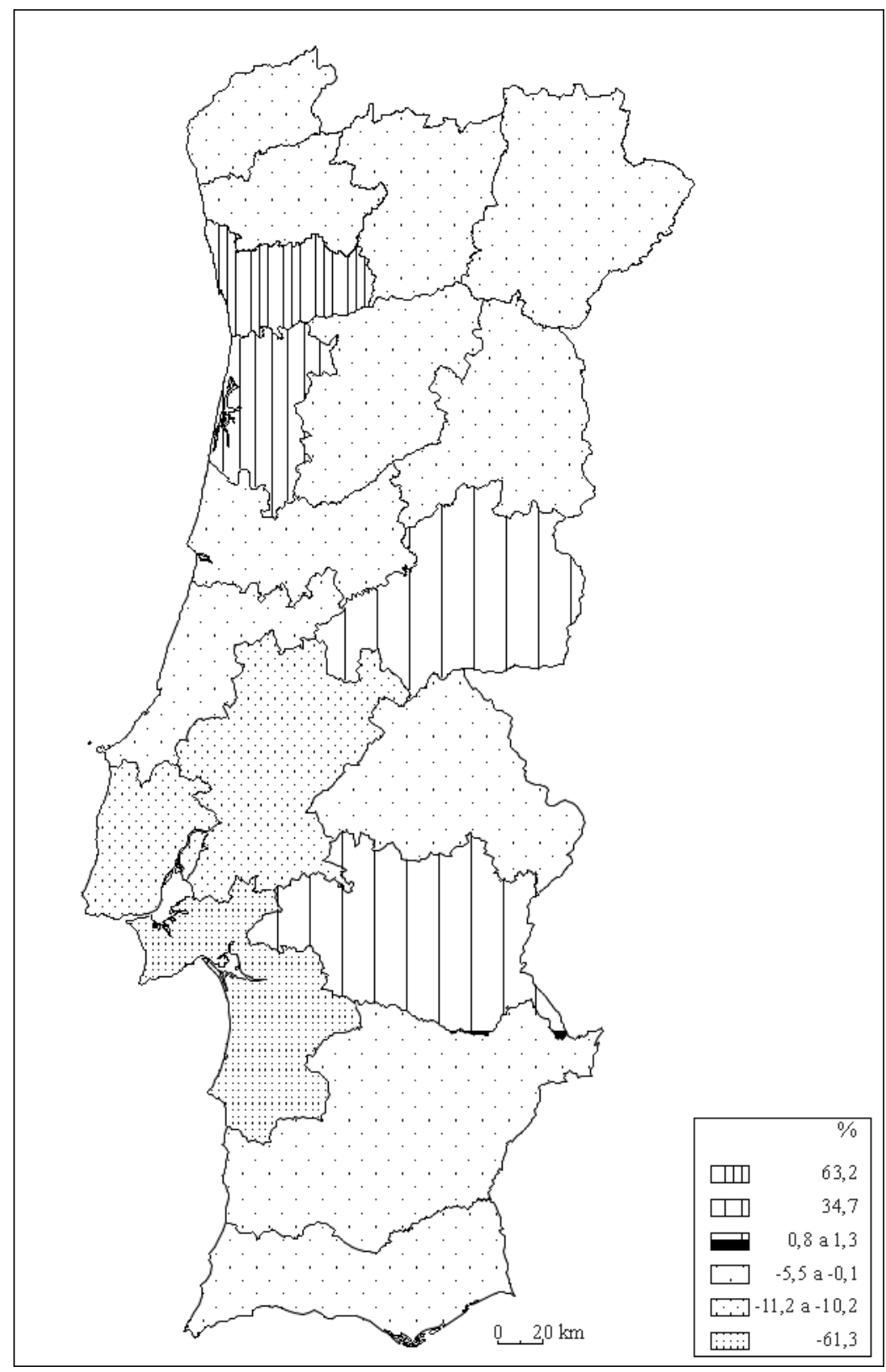

Figura 4 - Componente estrutural por distritos, 1982-93

(Valores percentuais calculados em relação ao total dos resultados com o mesmo sinal). Figure 4 - Proportional shift by «distrito», 1982-93 (\% on sum of positive values).

daquele encontrado nas décadas de sessenta (JENSEN-BUtLER e PIRES, 1983) e de setenta (FERRÃO e JENSEN-BUTLER, 1986), onde os distritos do litoral, possuindo estruturas industriais mais diversificadas, se opunham aos distritos do interior. Enquanto os primeiros apresentavam valores positivos para a Componente Estrutural, os segundos, sendo distritos menos industrializados e fortemente dependentes de ramos tradicionais como as alimentares e os têxteis, possuíam valores negativos.

$\mathrm{Na}$ década de oitenta, a forte incidência de valores negativos da Componente Estrutural explica-se pelo decréscimo do emprego no ramo dos têxteis e, com menor importância, no do material de transporte, que também apresenta taxas de crescimento negativo. O decréscimo do emprego no têxtil evidenciou-se não só nos distritos do interior cuja estrutura industrial era pouco diversificada (caso da Guarda) mas também nos distritos do litoral possuidores de estruturas menos 
débeis (caso de Coimbra). Relativamente ao material de transporte, o decréscimo do emprego foi bastante assinalável em distritos como Lisboa, Santarém, Setúbal, Viana de Castelo e Viseu, em muito contribuindo para os valores negativos da Componente Estrutural encontrados nestes distritos.

No entanto, é a componente diferencial que melhor explica o comportamento da ARL. Tal como já se verificava na análise de FERRÃO e JENSEN-ButLer (1986), a alteração relativa líquida associa-se mais com a componente diferencial do que com a componente estrutural, sendo o coeficiente de correlação de Pearson de 0,927 com a primeira e de 0,474 com a segunda. Poderemos mesmo dizer que a explicação pela componente diferencial se reforçou na última década, se atendermos ao valor de correlação encontrado no trabalho citado, $r=0,700$.

O padrão de distribuição da componente diferencial (fig. 5) mostra-nos que são os distritos que integram as duas Áreas Metropolitanas (AM's) (Lisboa, Setúbal e Porto), a que se juntam Faro, Bragança e Beja, que apresentam valores negativos para a Componente Diferencial. Para as AM's e para o distrito de Faro, os valores negativos derivam da continuidade do processo de terciarização a que têm sido sujeitos. Os casos de Bragança e de Beja, pelo contrário, explicam-se pela estagnação nos tecidos produtivos (manutenção de estruturas mais ligadas ao consumo local e consequentemente com um menor aproveitamento do capital industrial) o que lhes conferiu menor capacidade de integração no espaço nacional. Esta situação é ainda agravada pelo esvaziamento demográfico a que se tem vindo a assistir e que condicionou a capacidade de consumo regional.

Dos distritos que apresentam valores positivos, destacam-se com os valores mais elevados, Braga e, na generalidade, os distritos próximos das AM's e os situados ao longo do eixo Aveiro-Vilar Formoso. Tal padrão indicia um processo de desconcentração territorial, assente no aproveitamento das acessibilidades, da capacidade de integração territorial dos diversos ramos nestes distritos, bem como na maior capacidade de rendibilizar o capital industrial. Este último factor, é amplamente designado por «potencialidades endógenas» ou «desenvolvimento endógeno» e, como veremos adiante, em muito ajudará a explicar os padrões de desenvolvimento sectorial nos vários distritos do país. 


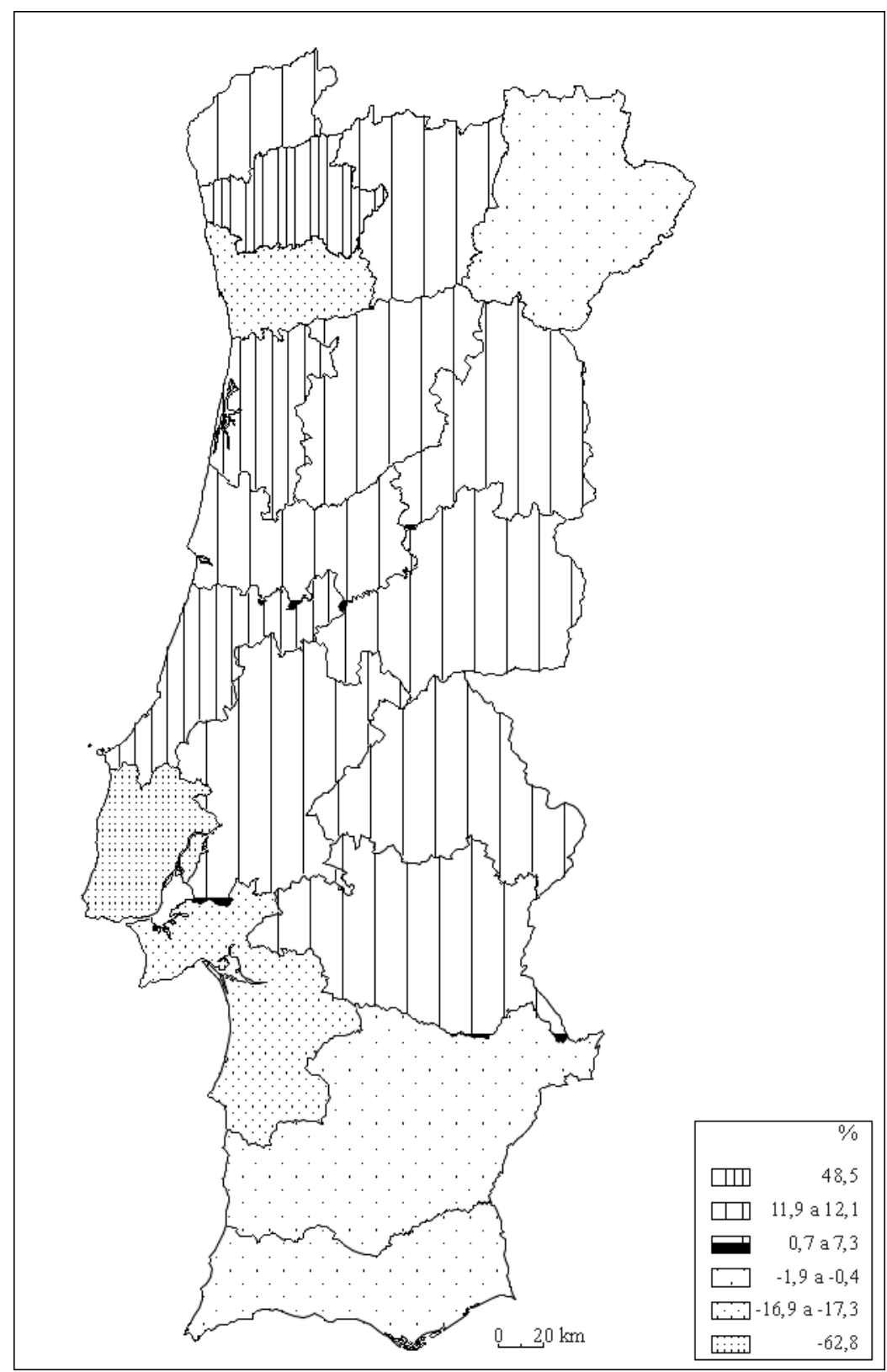

Figura 5 - Componente diferencial por distritos, 1982-93

(Valores percentuais calculados em relação ao total dos resultados com o mesmo sinal). Figure 5 - Differential shift by «distrito», 1982-93 (\% on sum of positive values).

O quadro III permite classificar os distritos segundo o seu comportamento face às componentes diferencial e estrutural. Comparando com os resultados da década de setenta (quadro IV), verificamos que apenas cinco distritos, num conjunto de dezoito, não alteram a sua posição na classificação proposta. São os distritos de Beja e Faro (valores negativos em ambas as componentes) e Braga, Vila Real e Guarda (valores negativos na componente estrutural e positivos na componente diferencial). Reportando-nos à década de sessenta, verificamos que apenas dois distritos mantêm a sua situação (Beja e Faro). 
Quadro III - Classificação dos distritos a partir das componentes estrutural e diferencial da evolução do emprego da indústria transformadora 1982-1993

Table III - «Distritos» classification on proportional and differential shift, 1982-1993

\begin{tabular}{|c|c|l|}
\hline $\begin{array}{c}\text { Componente } \\
\text { Estrutural }\end{array}$ & $\begin{array}{c}\text { Componente } \\
\text { Diferencial }\end{array}$ & Distritos \\
\hline+ & + & Aveiro, Castelo Branco, Évora \\
\hline- & + & $\begin{array}{l}\text { Braga, Coimbra, Guarda, Leiria, Portalegre, Santarém, } \\
\text { Viana do Castelo, Vila Real, Viseu }\end{array}$ \\
\hline+ & - & Porto \\
\hline- & - & Beja, Bragança, Faro, Lisboa, Setúbal \\
\hline
\end{tabular}

Quadro IV - Classificação dos distritos a partir das componentes estrutural e diferencial da evolução do emprego da indústria transformadora, 1960-70 e 1971-79

Table IV - «Distritos» classification on proportional and differential shift, 1960-1970 and 1971-1979

\begin{tabular}{|l|c|c|c|c|}
\hline & \multicolumn{2}{|c|}{$\mathbf{1 9 6 0 - 1 9 7 0}$} & \multicolumn{2}{c|}{ 1971-1979 } \\
\hline Distritos & C. Estrutural & C. Diferencial & C. Estrutural & C. Diferencial \\
\hline Aveiro & - & + & + & - \\
\hline Beja & - & - & - & + \\
\hline Braga & + & + & - & + \\
\hline Bragança & - & - & - & + \\
\hline Castelo Branco & + & - & + & + \\
\hline Coimbra & - & - & - & + \\
\hline Évora & - & + & - & - \\
\hline Faro & - & - & - & + \\
\hline Guarda & - & - & + & + \\
\hline Leiria & + & + & + & + \\
\hline Lisboa & - & - & + & + \\
\hline Portalegre & - & - & + & + \\
\hline Porto & + & + & + & + \\
\hline Santarém & - & - & + & + \\
\hline Setúbal & - & - & + & + \\
\hline Viana do Castelo & - & + & + & + \\
\hline Vila Real & - & + & + & + \\
\hline Viseu & - & + & + & + \\
\hline
\end{tabular}

Fonte: FERRÃO e JENSEN-BUTLER (1986). 


\section{2 - A Componente Diferencial: o comportamento das regiões}

Como se referiu, a ARL é fortemente explicada pelas características específicas de cada região. Assim, será interessante verificar o comportamento da componente diferencial em relação a alguns distritos, atendendo aos ramos que mais contribuiram para os seus resultados (quadro $\mathrm{V}$ ).

Quadro V - Ramos que mais contribuem para o resultado da componente diferencial em cada distrito

Table V - More significant branchs to differential shift

\begin{tabular}{|c|c|c|c|c|}
\hline Distritos & ARL & C.D. & Contribuição Positiva & Contribuição Negativa \\
\hline Aveiro & 17764 & 8464 & $\begin{array}{l}\text { Têxtil, Metálicas, Máquinas não } \\
\text { eléctricas, Máquinas e material } \\
\text { Eléctrico, Material Transporte }\end{array}$ & Calçado \\
\hline Beja & -346 & -299 & Vestuário, Madeiras & $\begin{array}{l}\text { Alimentares, Mobiliário, } \\
\text { Máquinas não eléctricas }\end{array}$ \\
\hline Braga & 34277 & 34389 & Têxtil, Vestuário & \\
\hline Bragança & -524 & -441 & Metálicas & Alimentares \\
\hline Castelo Branco & 1515 & 1311 & Vestuário, Material Eléctrico & Têxtil \\
\hline Coimbra & 587 & 739 & Alimentares, Papel, Metálicas & Têxtil,Porcelana e Faiança \\
\hline Évora & 895 & 550 & $\begin{array}{l}\text { Outros minerais não metálicos, } \\
\text { Material Transporte }\end{array}$ & $\begin{array}{l}\text { Alimentares, Material Eléc- } \\
\text { trico }\end{array}$ \\
\hline Faro & -1822 & -1348 & & Alimentares \\
\hline Guarda & 1500 & 2983 & Vestuário, Material Eléctrico & \\
\hline Leiria & 7378 & 8606 & $\begin{array}{l}\text { Vestuário, Porcelana e Faiança, } \\
\text { Metálicas }\end{array}$ & \\
\hline Lisboa & -47591 & -44587 & & $\begin{array}{l}\text { Vestuário, Metálicas, Mate- } \\
\text { rial Eléctrico }\end{array}$ \\
\hline Portalegre & 756 & 1042 & Químicos & Têxtil \\
\hline Porto & 4661 & -12282 & Calçado, Material Eléctrico & Têxtil, Vestuário \\
\hline Santarém & 261 & 3105 & $\begin{array}{l}\text { Couros e curtumes, Material } \\
\text { Transporte }\end{array}$ & $\begin{array}{l}\text { Vestuário, Máquinas não } \\
\text { eléctricas }\end{array}$ \\
\hline Setúbal & -28418 & -11988 & Material eléctrico & $\begin{array}{l}\text { Vestuário, Produtos metáli- } \\
\text { cos, Material Transporte }\end{array}$ \\
\hline $\begin{array}{ll}\text { Viana } & \text { do } \\
\text { Castelo } & \\
\end{array}$ & 4016 & 4044 & Vestuário, Madeiras & \\
\hline Vila Real & 314 & 512 & Alimentares, Metálicas & $\begin{array}{l}\text { Ind. Metálicas básicas não } \\
\text { ferrosos }\end{array}$ \\
\hline Viseu & 4775 & 5200 & $\begin{array}{l}\text { Alimentares, Vestuário, } \\
\text { Metálicas }\end{array}$ & \\
\hline
\end{tabular}

A observação do quadro $\mathrm{V}$ poderá levar-nos a pensar na existência de contradições pela contribuição negativa e simultaneamente positiva de alguns ramos. No entanto, estas contradições são apenas aparentes, traduzindo antes posicionamentos diferenciados nos territórios em análise e realçando especificidades locais que lhes conferem vantagens ou desvantagens locativas. Se observarmos o comportamento do ramo das indústrias alimentares, verificamos que onde ocorreu o esvaziamento do mercado local e onde se verificava uma excessiva associação à actividade agrícola, a contribuição foi negativa, enquanto nos distritos que assumiram novas centralidades e maior dinamismo urbano, as suas contribuições foram positivas. Significa então, que o primeiro grupo de distritos não reuniu condições favoráveis para as unidades do ramo alimentar, caso de alguns distritos do interior. Pelo contrário, no segundo grupo, as vantagens 
locativas foram evidentes (mercado, acessibilidade, novos padrões de consumo), contribuindo para o maior dinamismo deste ramo.

Os valores encontrados para o distrito de Lisboa reflectem o processo de reestruturação produtiva que se observou ao longo da década de oitenta. O decréscimo do emprego industrial é generalizado, mas adquiriu particular dimensão nos ramos do vestuário, dos produtos metálicos e no material eléctrico, continuando Lisboa a perder vantagens relativas em termos de localização (fig. 6a e $6 b)$.

Esta situação reflecte a divisão territorial do trabalho ao nível nacional. Os custos salariais mais elevados e o maior nível de organização da força de trabalho, tiveram como resposta a deslocalização de ramos intensivos em força de trabalho (caso do vestuário). Por outro lado, a crise internacional, que afectou de forma mais significativa as indústrias pesadas, fez-se sentir de forma particular no distrito de Lisboa, bem como no distrito de Setúbal, onde estas eram mais representativas (químicas, produtos metálicos e material de transporte). Esta situação tinha sido já referida por BUTLER e FERRÃO (1986) na década anterior.

$\mathrm{O}$ distrito do Porto, durante a década de oitenta, viu alteradas as suas vantagens locativas. Os ramos que mais contribuiram negativamente foram o têxtil e o vestuário, situação que é consideravelmente diferente da vivida na década anterior. Nos anos setenta, o distrito do Porto integrava-se no conjunto de distritos do norte litoral do país que apresentavam vantagens de localização para a produção do têxtil e do vestuário, tendo-as perdido posteriormente para o calçado. Efectivamente, nos anos oitenta a concorrência internacional na fileira têxtil aumentou significativamente devido à afirmação de novos produtores ao nível mundial capazes de produzir a baixos custos. Neste contexto, foram os distritos onde os custos de produção eram mais altos que perderam vantagens relativamente a outros. É o caso do Porto, onde o nível de desenvolvimento urbano e o de mobilização da força de trabalho elevaram os custos salariais, retirando-lhe vantagens de localização para segmentos de produção com baixa incorporação tecnológica e de reduzida qualidade. No caso do calçado, o Porto ganhou vantagens, nomeadamente em relação a Aveiro, tradicional centro produtor, uma vez que a sua estrutura de qualificações e os níveis salariais praticados neste ramo são mais baixos do que neste último distrito, onde o calçado está associado a unidades com maior capacidade competitiva em termos internacionais (quadro VI). 


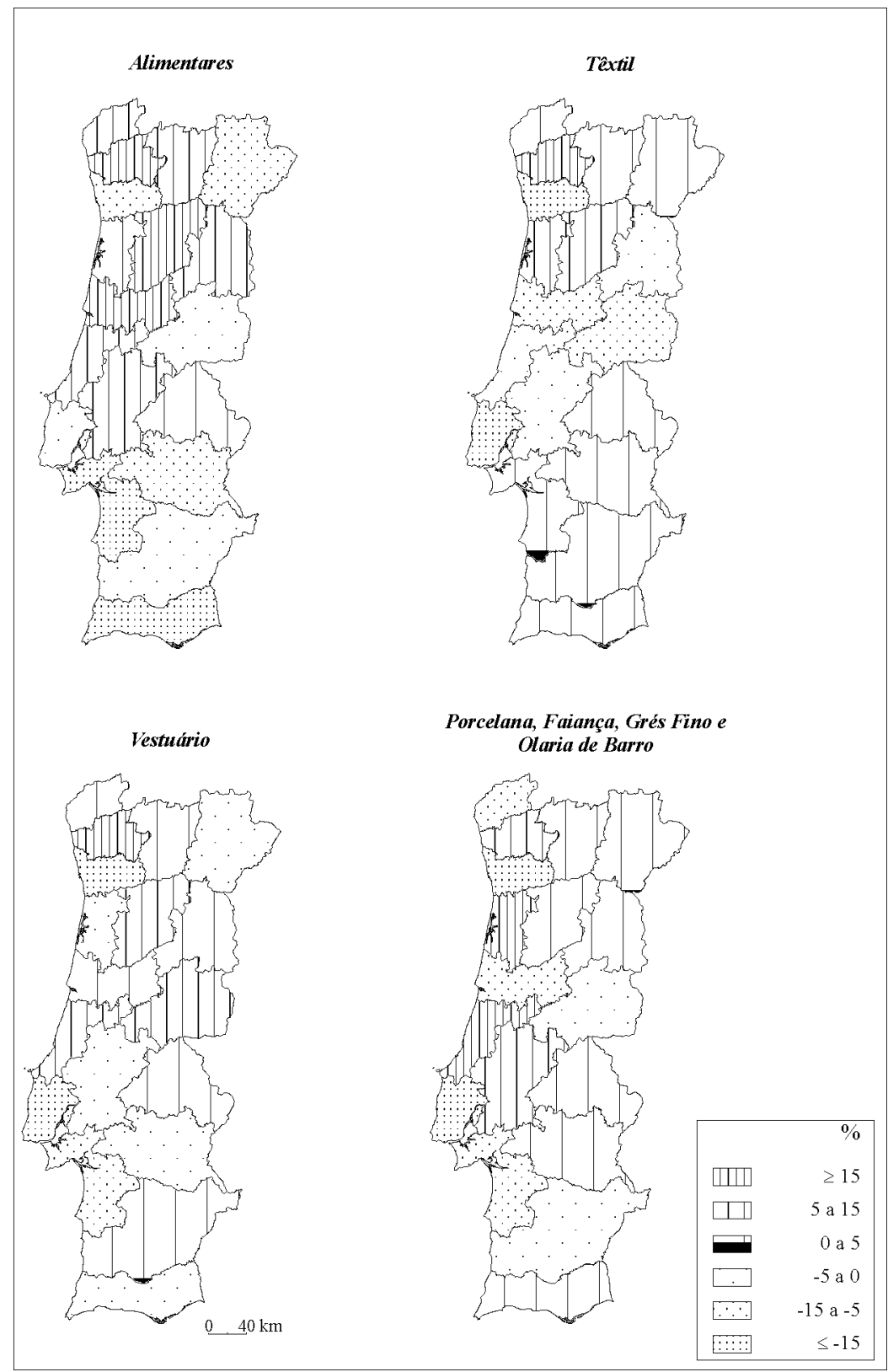

Figura 6a - Componente diferencial em alguns ramos, por distritos, 1982-93 (Valores percentuais calculados em relação ao total dos resultados com o mesmo sinal) Figure 6a - Differential Shift of some branches by «Distrito», 1982-93 ( $\%$ on sum of positive values). 


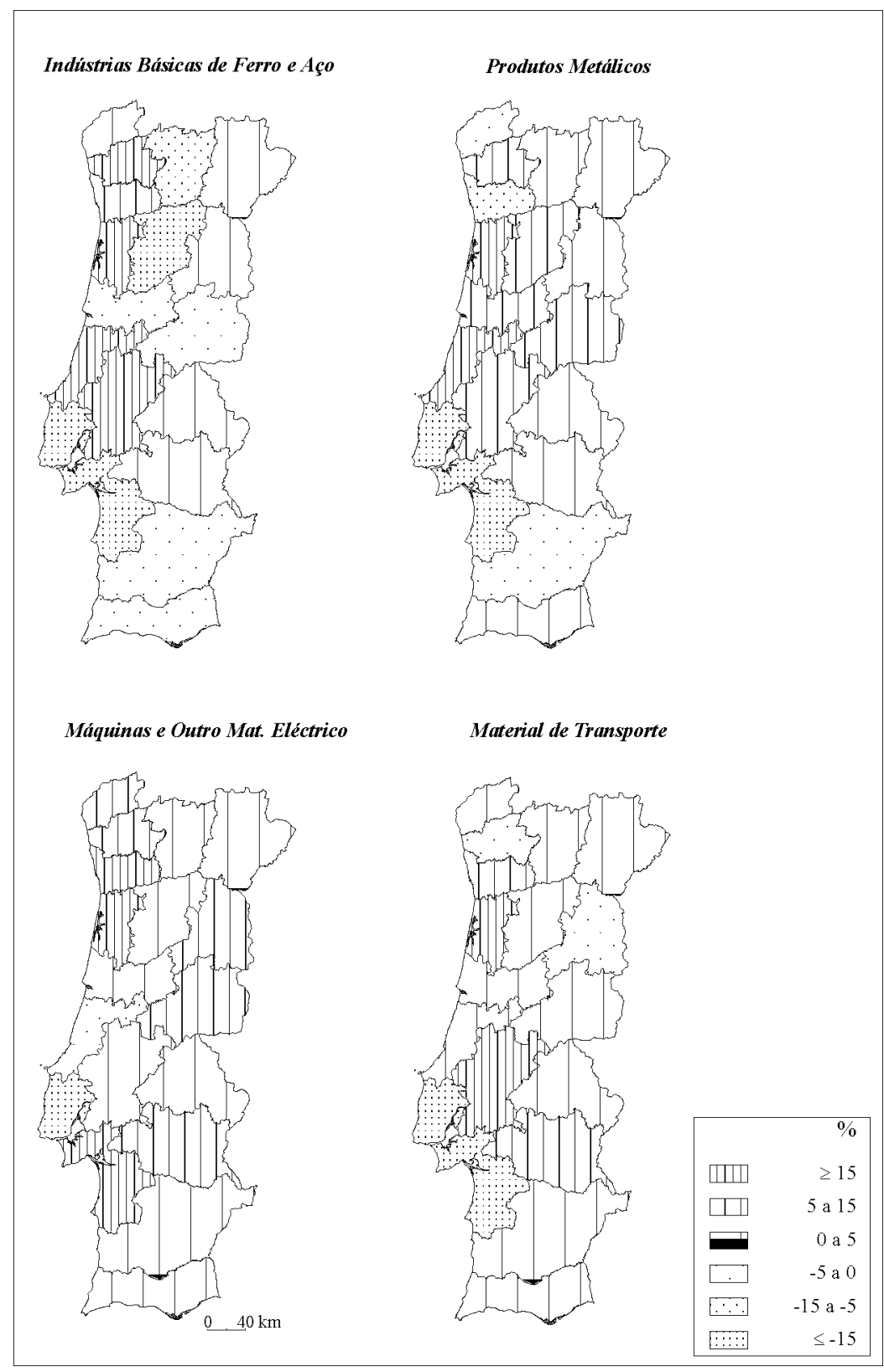

Figura 6b - Componente diferencial em alguns ramos, por distritos, 1982-93

(Valores percentuais calculados em relação ao total dos resultados com o mesmo sinal). Figure 6b - Differential Shift of some branches by «Distrito», 1982-93 ( $\%$ on sum of positive values). 
Quadro VI - Estrutura do emprego no ramo do calçado segundo os níveis de qualificação, em alguns distritos do País, 1993 (\%)

Table VI - Employment in shoe branch, by level of qualification, in some «distritos», 1993 (\%).

\begin{tabular}{|l|r|r|r|r|r|r|r|}
\hline Áreas & $\begin{array}{c}\text { Q.Superiores } \\
\text { e Médios }\end{array}$ & $\begin{array}{c}\text { Encar.,Cont., } \\
\text { Ch,Equipa }\end{array}$ & $\begin{array}{c}\text { Prof.Alt. } \\
\text { Qual. e } \\
\text { Qual.. }\end{array}$ & $\begin{array}{c}\text { Prof.Semi Qual. } \\
\text { e Não Qual. }\end{array}$ & $\begin{array}{c}\text { Prat. e } \\
\text { Aprendizes }\end{array}$ & Ignorado & Total \\
\hline Aveiro & 0,6 & 1,1 & 32,3 & 43,1 & 17,8 & 5,0 & 100,0 \\
\hline Braga & 1,2 & 1,8 & 31,5 & 38,2 & 24,2 & 3,1 & 100,0 \\
\hline Porto & 0,7 & 1,6 & 26,1 & 45,2 & 22,7 & 3,8 & 100,0 \\
\hline Continente & 0,7 & 1,4 & 28,8 & 42,6 & 22,2 & 4,3 & 100,0 \\
\hline
\end{tabular}

Fonte: MESS, 1993.

Neste contexto, o distrito de Braga continua a apresentar para o ramo do vestuário valores da componente diferencial altamente positivos. A coexistência de uma actividade agrícola complementar da industrial, os ganhos de acessibilidade e a proximidade ao Porto, constituem vantagens desta área. A actividade agrícola, ao ser encarada como um reforço do orçamento familiar, tem dado cobertura ao pagamento de salários mais baixos, o que tem beneficiado os ramos cujas características tecnológicas e organizativas se baseiam na intensificação do factor trabalho. Tais condições atraem o capital estrangeiro que tem uma expressão assinalável nestes ramos. Por outro lado, este contexto é favorável à proliferação de empresas de reduzida dimensão que se inserem no mercado pelo estabelecimento de relações de subcontratação com outras empresas.

A sul do Porto, o distrito de Aveiro possui vantagens relativas num vasto leque de ramos, em que se destaca a obtenção de produtos metálicos, máquinas, material eléctrico e não eléctrico e material de transporte. As relações inter-industriais e a existência de um tecido empresarial com tradição permitiu o simultâneo crescimento do emprego e do número de unidades produtivas, do qual é exemplo a metalomecânica, ramo com forte tradição, nomeadamente no concelho de Águeda. O processo de desenvolvimento local, amplamente evidenciado por REIS (1992), parece ter constituído uma resposta muito positiva às contingências que caracterizaram o processo de desenvolvimento industrial na década em estudo. Assim, o crescimento da metalomecânica esteve associado à expansão de outras actividades (fabrico de mobiliário ou material eléctrico) e à divisão do trabalho industrial (fundição, moldes, ferramentas, cromagem, tornearia).

O comportamento do ramo do têxtil, e também do vestuário, em Aveiro, teve por base o aproveitamento da mão-de-obra feminina, que gradualmente foi participando em ramos identicamente significativos em termos de emprego local. A crescente feminização da força de trabalho decorre da absorção da mão-de-obra que abandonou a actividade agrícola ou diminuiu o tempo de actividade neste sector.

O distrito de Leiria manifesta algumas características comuns ao de Aveiro. A difusão de unidades fabris deu origem a um território com características urbano-industriais, onde a pluriactividade se expressa de diversas formas (LOURENÇO, 1991). Estas condições surgem, mais uma vez, como «vantagens locativas» para a difusão de certos ramos industriais. A estrutura industrial permite revelar a importância que assumem as metálicas, as porcelanas, faianças e o vestuário (quadro V), actividades que, com excepção para o vestuário, são tradicionais especializações territoriais. A instalação de unidades industriais ligadas à produção de vidro, que remonta ao século XVIII, permitiu que desde cedo se desenvolvesse a actividade complementar de produção de moldes. A especificidade tecnológica constitui um 
potencial para que posteriormente se viesse a afirmar a produção de moldes para plástico. A especialização na indústria de porcelana e faiança afirmou-se também muito cedo, surgindo associada ao aproveitamento de recursos locais por parte de uma classe empresarial local (FEIO, 1994).

$\mathrm{O}$ distrito de Viseu apresenta vantagens locativas face a um conjunto de ramos, como sejam as alimentares, as bebidas, as metálicas e o vestuário. A vantagem das indústrias alimentares e das bebidas é em larga medida explicada pela associação com um sector agrícola dinâmico, cujas produções se destinam, em grande parte, à transformação e comercialização (caso dos vinhos e dos frutos). Por outro lado, as indústrias metálicas encontram um mercado regional importante, nomeadamente para a produção de peças e máquinas para a agricultura (factor que justifica a tradição desta actividade em Viseu) bem como de materiais para a construção civil. O forte crescimento do emprego ligado à produção de materiais para a construção civil decorre do desenvolvimento urbano bem como da dinâmica de construção de residências secundárias no meio rural, nomeadamente por parte de emigrantes. $\mathrm{O}$ aumento da centralidade face ao território nacional, bem como à vizinha Espanha, permitiu que esta actividade se estendesse a outros mercados (GAMA, 1995), reforçando a vantagem relativa de Viseu.

A evolução dos restantes distritos foi condicionada pelo decréscimo populacional e consequente envelhecimento das estruturas demográficas. Assim se explica a perda de vantagens de localização para as indústrias alimentares e do mobiliário (exemplos de Beja e Bragança). No entanto, o acentuar da urbanização, traduzido no aumento da população residente em lugares de maior dimensão, parece contrariar o movimento anterior conferindo novas vantagens locativas a estes espaços. Efectivamente, as vantagens de localização dos distritos do interior confinam-se em grande parte aos centros urbanos, onde se concentram população (mais jovem e mais qualificada), actividades e as infra-estruturas de apoio à actividade produtiva. Deste modo, compreende-se assim que os distritos da Guarda, Castelo Branco e Évora ofereçam vantagens de localização para a produção de vestuário, material eléctrico ou material de transporte, ramos onde o nível de internacionalização do capital é elevado. Este aparece associado aos baixos custos salariais, disponibilidade de mão-de-obra feminina, concessão de incentivos à localização por parte dos agentes locais (que também têm sido importantes em outras áreas do país) e à melhoria generalizada da acessibilidade.

\section{CONCLUSÃO}

A análise das dinâmicas de crescimento do emprego industrial mostra que as modificações ocorridas durante a década de oitenta foram incipientes, não se tendo registado, com excepção para os distritos de Lisboa e do Porto, grandes alterações de carácter estrutural. $\mathrm{O}$ vestuário, o calçado e o mobiliário, tradicionais ramos exportadores, reforçaram a sua posição, ao mesmo tempo que se afirmaram alguns segmentos de especialização industrial, como sejam a produção de material eléctrico, produção de porcelanas e faianças, fortemente viradas para o mercado externo. Por outro lado, acentuou-se o declínio da indústria pesada (químicas, metalúrgicas de base e material de transporte). O aproveitamento dos incentivos comunitários em pouco alteraram o perfil de especialização da indústria portuguesa, tendo-se verificado uma concentração sectorial dos investimentos efectuados.

Os reflexos territoriais das mudanças ocorridas podem ser sintetizados em quatro vectores: a manutenção do movimento de desconcentração produtiva a 
partir dos grandes centros urbanos, de que Lisboa é o melhor exemplo; o decréscimo do emprego industrial em distritos onde se fez sentir de forma acentuada o declínio e envelhecimento populacional (casos de Bragança e Beja); reforço da importância dos distritos adjuntos às Áreas Metropolitanas de Lisboa e do Porto, cujas vantagens locativas decorrem da proximidade aos grandes centros urbanos e de uma melhoria da acessibilidade (Aveiro, Braga, Santarém, Leiria e Viseu); e o crescimento de distritos do interior, tais como Castelo Branco e Guarda, associado a uma forte componente exógena do capital e ao papel dos agentes de dinamização local.

Assim, a reconfiguração dos espaços produtivos reflecte dois aspectos de fundamental importância: a manutenção da litoralização no que diz respeito à localização de ramos/empresas mais dinâmicas e competitivas e um maior realce das especificidades de natureza local e regional nas dinâmicas de crescimento do emprego industrial.

\section{BIBLIOGRAFIA}

BAPTISTA, A.; J. FERRÃo (1989) - Industrialização e desenvolvimento endógeno em Portugal: problemas e perspectivas. Sociologia - Problemas e Práticas, 7: 43-64.

BOURA, I.; F. COSTA; R. JACINTO (1993) - Políticas de desenvolvimento industrial: novas estratégias, uma velha geografia. in CCRC. (ed.). Serviços e Desenvolvimento numa região em mudança, CCRC, Coimbra: 335-357.

Brito, J. M. B.; V. Martins; A. Mateus (1995) - Portugal XXI - Cenários de Desenvolvimento. Bertrand Editora, Venda Nova.

CAETANO, L.; R. JACINTO (1990) - Contributo para o estudo do processo de industrialização em áreas marginais da Região Centro. in CCRC. (ed.). Industrialização em meios rurais e competitividade internacional, CCRC, Coimbra: 53-73.

CARDoso, A.R. (1994) - Regional wage inequality in Portugal. Estudos de Economia, XIV (4): 429-449.

CostA, E. M. (1992) - Reestruturação Económica e Desenvolvimento Local. O caso de Castelo Branco. Dissertação de mestrado em Geografia apresentada à Faculdade de Letras da Universidade de Lisboa.

CostA, E. M.; I. PIRES (1995) - A estrutura industrial do território raiano entre Alto Trás-os-Montes e Beira Interior Sul. in C. CAVACo (ed.). As Regiões de Fronteira, Inovação e desenvolvimento na perspectiva do Mercado Único Europeu, Centro de Estudos Geográficos, Lisboa: 103-143.

Costa, N.; M. VAle (1995) - The Impact of AutoEuropa in the National and Regional Development in Portugal. Comunicação apresentada na conferência Consequências da integração europeia: aspectos regionais e económicos - O caso português, CEG, Lisboa.

FEIO, P. A. (1994) - Território e Internacionalização das empresas portuguesas, Um estudo de caso no sector da cerâmica. Dissertação de mestrado em Geografia apresentada à Faculdade de Letras da Universidade de Lisboa.

FERRÃO, J. (1987) - Indústria e valorização do capital. Uma análise geográfica. Centro de Estudos Geográficos, Lisboa.

GAMA, R. (1995) - Multinacionais e pequenas empresas no desenvolvimento territorial: o exemplo de Mangualde. in Actas do II Congresso da Geografia Portuguesa, Vol. I, Associação Portuguesa de Geógrafos: 385-400.

Guimarães, R.; M. Martins (1986) - Indústria Transformadora. in M. Silva (ed.). Portugal Contemporâneo, Problemas e Perspectivas, Cap. 12, INA, Lisboa: 253-274. 
JenSEn-Butler, C.; J. FerRão (1986) - Desenvolvimento industrial e diferenciações regionais em Portugal, durante a década de setenta. Finisterra. Revista Portuguesa de Geografia, XXI (42): 203-238.

JENSEN-Butler, C.; I. PIRES (1983) - Industrial structure and regional development in Portugal. Working Paper 13, Geographical Institute, University of Aarhus, Aarhus.

LOUREnÇO, N. (1991) - Família Rural e Indústria, Mudança Social na Região de Leiria. Editorial Fragmentos, Lisboa.

MARQUES, M. (1992) - Subcontratação e autonomia empresarial - Um estudo sobre o caso português. Ed. Afrontamento, Porto.

Matos, S. (1973) - Investimento estrangeiro em Portugal - Alguns aspectos. Seara Nova, Lisboa.

MIE (1990) - Indústria e Energia, Evolução 1989 e Perspectivas 1990. Ministério da Indústria e Energia, Lisboa.

MIE (1993) - PEDIP, Relatório de Execução 1988-1992. Ministério da Indústria e Energia, Lisboa.

MESs (1994) - Demografia das Empresas - 1982-1992. Ministério do Emprego e Segurança Social, Lisboa.

PIMENTA, C. (1984) - Economia Portuguesa. Uma experiência, uma análise. Editorial Caminho, Lisboa.

PIRES, A.R. (1986) - Industrialização difusa e modelo de desenvolvimento: um estudo no distrito de Aveiro. Finisterra. Revista Portuguesa de Geografia, XXI (42): 239-269.

PIRES, A.R. (1990) - A pluriactividade e as políticas agrícolas. in CCRC (ed.). Industrialização em meios rurais e competitividade internacional, CCRC, Coimbra: 199-218.

PIRES, I. (1995) - Reestruturação de uma região industrial tradicional: a Beira Interior e a indústria de lanifícios. in CAVACO. C. (ed.). As Regiões de Fronteira, Inovação e desenvolvimento na perspectiva do Mercado Único Europeu, Centro de Estudos Geográficos, Lisboa: 145-167.

REIS, J. (1992) - Os Espaços da Indústria, A regulação económica e o desenvolvimento local em Portugal. Edições Afrontamento, Porto.

Rodrigues, M. J.; O. NeVES et al. (1994) - Políticas de Reestruturação, Emprego e Desenvolvimento Regional. Instituto de Emprego e Formação Profissional, Lisboa.

SARAIVA, A. M. (1993) - Investimento Directo Estrangeiro em Portugal no período de 1986 a 1992. Boletim Trimestral do Banco de Portugal, 15 (4): 103-124.

VALE, M. (1991) - A internacionalização da economia e a indústria electrónica em Portugal. Actas do V Colóquio Ibérico de Geografia, Leon: 525-533. 